\title{
Analysis of windlass sprocket wheel intensity
}

\author{
Yang-yang Shi, Zhi-ming Wang , Jian Zheng and Ning Zhang \\ Institute of Mechanical Engineering, Nanjing University of Science and Technology, 210094 Nanjing, China
}

\begin{abstract}
The multi-body dynamics model of windlass was established by RecurDyn and Pro/E in this paper, and the multi-body dynamics simulation was also conducted. According to the results of the multi-body dynamics simulation, structural static analysis on sprocket wheel in dangerous conditions were executed by ANSYS Workbench. The results showed that there are three bearing situations in the meshing transmission process of sprocket wheel and chain: Single tooth bearing, two tooth bearing and carrying equal contact force and two tooth bearing but one tooth contact force reaches the maximum value. The equivalent stress value at the contact position of sprocket wheel and chain exceeds the yield stress of the chain wheel material, but it does not cause damage to chain wheel. In addition to the contact location, the equivalent stress value of the remaining parts of sprocket wheel are in the allowable stress range of sprocket wheel material, comply with the requirement of strength design.
\end{abstract}

\section{Introduction}

Windlass is an equipment to overcome the external force in the work phase of anchor and keep the stablility of the ship. It ensures the safety of the ship when it leave away from the dock and in case of emergency braking. Safe and reliable operation of the windlass directly affect normal operation and operational safety of the ship. The anchor of windlass is implemented by meshing transmission process of sprocket wheel and chain. Therefore, the normal work of sprocket wheel is essential for windlass.

Design and Verification on windlass components are based on empirical formulas and simple mechanical models currently [1], such as Zhou Zhong-wang, Fang Lian-xing [2-3]. Their calculation of the load in the sprocket shaft and the base by finite element analysis are different from the actual load when the windlass working. In this paper, the sprocket wheel was studied, and the multi-body dynamics model of windlass was established by RecurDyn and multi-body dynamics simulation was also conducted. The mechanical characteristics of sprocket wheel during operation were analyzed and the dangerous working conditions of sprocket wheel were determined. The strength of sprocket wheel were analyzed by ANSYS Workbench.

\section{Brief introduction of sprocket wheel}

Since the shape of sprocket wheel is so complex, it is generally made by casting fabrication [4], and chain are also blank parts, they both have large manufacturing errors. Therefore, there is slip phenomenon in the sprocket wheel nest in the meshing transmission process of sprocket wheel and chain. It caused abrasion in the tooth surface of sprocket wheel. The meshing transmission between sprocket wheel and chain belongs to circular chain meshing transmission. There are frequent shocks between sprocket wheel and chain in the meshing transmission process [5]. So the sufficient strength of sprocket wheel is required.

In this paper, the diameter of the hydraulic windlass anchor is $78 \mathrm{~mm}$. Sprocket wheel is a five gears of A type. Its material is GS-52, and the yield strength is $260 \mathrm{MPa}$. Its tooth structure is shown in Fig. 1. According to People's Republic of China shipbuilding industry $\mathrm{CB} / \mathrm{T}$ 3179-1996 <sprocket wheel> Standard [6], the main structural parameters are as follows: the pitch circle's diameter is $1062 \mathrm{~mm}$, namely when the sprocket wheel meshing with a chain, circumscribed circle diameter of the regular polygon formed by the center line of chain, can be used as the calculation diameter when sprocket wheel transfering torque. The speed calculation diameter is $993 \mathrm{~mm}$, used as the calculation diameter which determines the anchor's mobile line speed when anchor handling.
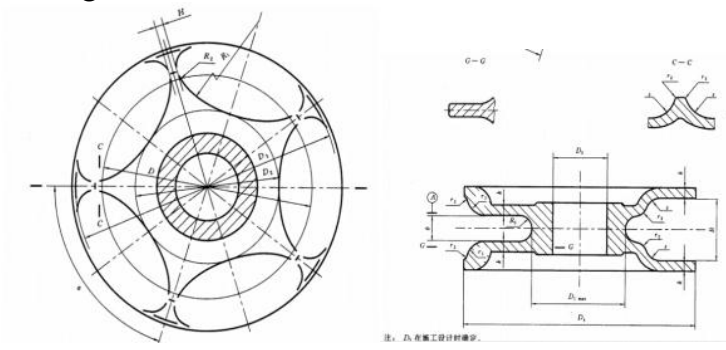

Figure 1. Tooth-shaped structure of five gears sprocket wheel. 


\section{Windlass multi-body dynamics model building and analysis of results}

Since the shape of sprocket wheel is so complex, it is generally made by casting fabrication [4], and chain are also blank parts, they both have large manufacturing errors. Therefore, there is slip phenomenon in the sprocket wheel nest in the meshing transmission process of sprocket wheel and chain. It caused abrasion in the tooth surface of sprocket wheel. The meshing transmission between sprocket wheel and chain belongs to circular chain meshing transmission. There are frequent shocks between sprocket wheel and chain in the meshing transmission process [5]. So the sufficient strength of sprocket wheel is required.

\subsection{Multi-body dynamics model building}

\subsubsection{Import and process of solid models of windlass}

The windlass, chain and chain stopper are interferencefree assembled in Pro/E [7] and save as a Parasolid file, then import it to RecurDyn. Set units to "MMKS", adjust the direction of gravity for the $\mathrm{Z}$-axis positive direction, the remaining parameters keep the default settings. Use Merge function to merge every parts of windlass, the assembly model of windlass is shown in Fig. 2 after the merger. The name of the components are shown in table 1 .

Table 1. Name of the components

\begin{tabular}{|c|c|c|c|}
\hline Number & Name & Number & Name \\
\hline 1 & $\begin{array}{c}\text { Chain } \\
\text { stopper }\end{array}$ & 7 & $\begin{array}{c}\text { Spindle } \\
\text { support } \\
\text { base }\end{array}$ \\
\hline 2 & Chain & 8 & $\begin{array}{c}\text { Sprocket } \\
\text { wheel base }\end{array}$ \\
\hline 3 & $\begin{array}{c}\text { Sprocket } \\
\text { wheel }\end{array}$ & 9 & $\begin{array}{c}\text { Sprocket } \\
\text { wheel gear } \\
\text { module }\end{array}$ \\
\hline 4 & $\begin{array}{c}\text { Pre-axis } \\
\text { module }\end{array}$ & 10 & $\begin{array}{c}\text { Roll } \\
\text { module 1 }\end{array}$ \\
\hline 5 & $\begin{array}{c}\text { Spindle } \\
\text { module }\end{array}$ & 11 & $\begin{array}{c}\text { Roll } \\
\text { module 2 }\end{array}$ \\
\hline 6 & $\begin{array}{c}\text { Spindle } \\
\text { module }\end{array}$ & 12 & --------- \\
\hline
\end{tabular}

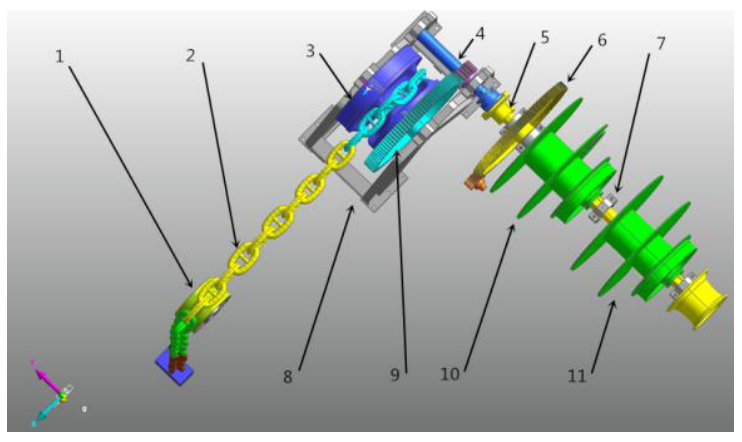

Figure 2. Assembly model of windlass.

\subsubsection{Windlass model constraints exerts}

According to the working principle of the various components of the windlass, constraints for various components of the windlass are added, they are shown in table 2 .

Table 2. Constraints for various components

\begin{tabular}{|l|l|}
\hline Constraint objects & $\begin{array}{l}\text { Constraint } \\
\text { name }\end{array}$ \\
\hline Chain stopper and earth & Revolute Joint \\
\hline $\begin{array}{l}\text { Sprocket wheel and sprocket wheel } \\
\text { base }\end{array}$ & Revolute Joint \\
\hline $\begin{array}{l}\text { Sprocket wheel and sprocket wheel } \\
\text { gear }\end{array}$ & $\begin{array}{l}\text { Perpendicular } \\
\text { Joint }\end{array}$ \\
\hline Pre-axis module and pre-axis pinion & Fixed Joint \\
\hline Spindle and spindle bearing & Revolute Joint \\
\hline Gearbox pinion and earth & Revolute Joint \\
\hline Sprocket wheel base and earth & Fixed Joint \\
\hline $\begin{array}{l}\text { Sprocket wheel gear and sprocket } \\
\text { wheel base }\end{array}$ & Revolute Joint \\
\hline $\begin{array}{l}\text { Pre-axis module and sprocket wheel } \\
\text { base }\end{array}$ & Revolute Joint \\
\hline Spindle support base and earth & Fixed Joint \\
\hline Gearbox gear and spindle & Fixed Joint \\
\hline Roll module 1,2 and spindle bearing & Fixed Joint \\
\hline
\end{tabular}

\subsubsection{Windlass model exposure modeling}

The contact between various components of the windlass use the Extended Surface To Surface in RecurDyn, such as the contact between chain and chain stopper, chain and chain, chain wheel and chain.

\subsubsection{Windlass model-driven load}

The speed of the anchor must be greater than or equal to $0.15 \mathrm{~m} / \mathrm{sec}$ in the working phase of anchor. The speed of gearbox pinion is $24 \mathrm{rad} / \mathrm{s}$. To reduce the impact of sudden changes in velocity, load is applied by STEP function[8-9]. Gearbox pinion angular velocity-time curve graph is shown in Fig. 3.

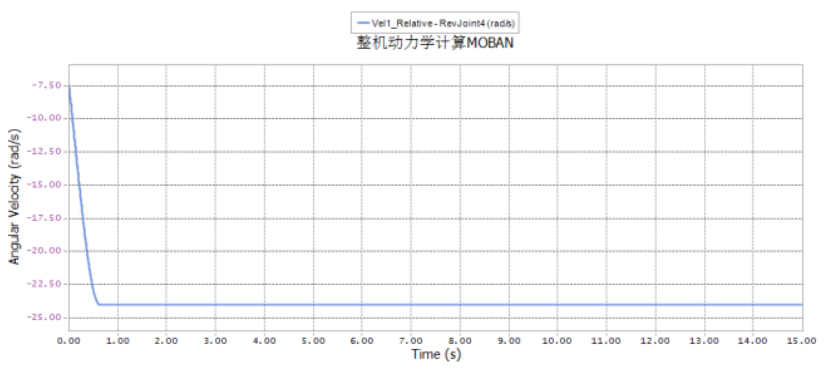

Figure 3. Gearbox pinion angular velocity-time curve graph. 


\subsubsection{Virtual prototype test}

Virtual prototype needs to be tested after created. Preanalysis results of windlass virtual prototype model are shown in Fig. 4. It can be drawn that windlass model established in this paper contains 67 parts, 111 surface contact (extended surface contact), 304 degrees of kinematics freedomand and no redundant constraints. Model validation is correct.

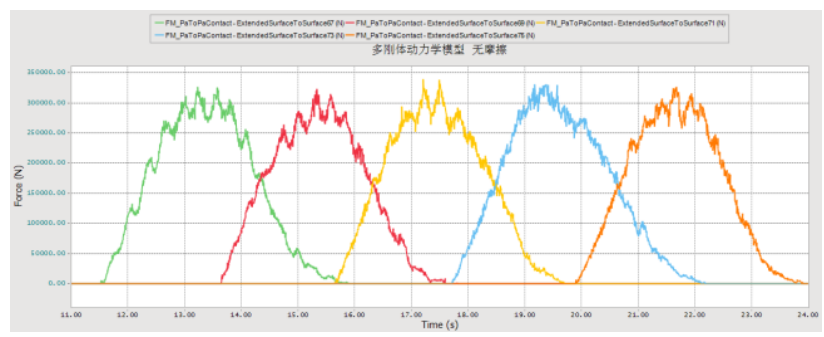

Figure 4. Pre-analysis results.

\subsection{Analysis of Kinetic simulation results}

Composition of contact force graph between sprocket wheel and chain during the working phase of anchor is shown in Fig. 5.

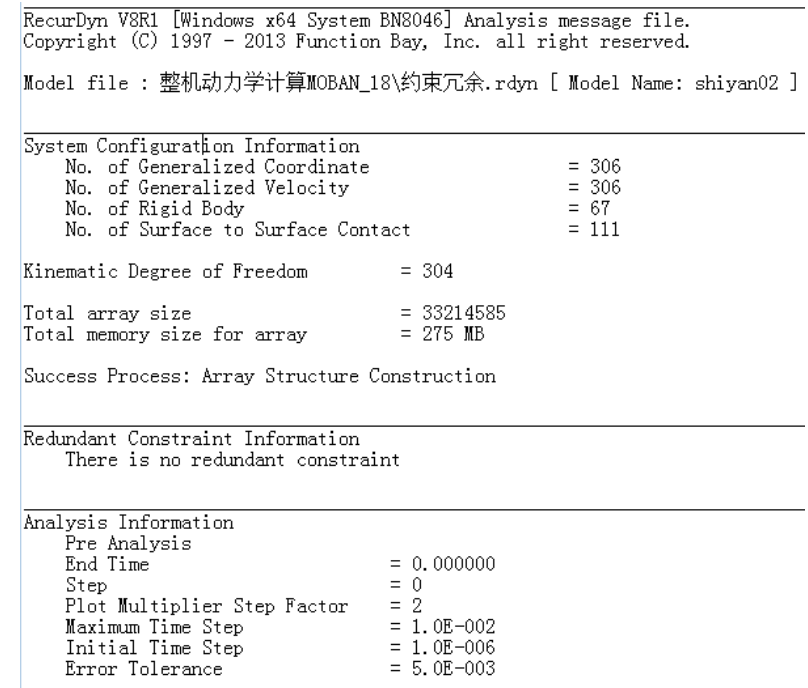

Figure 5. Composition of contact force.

The analysis of results from figure 5 are listed as follows:

1. The number of chain are no more than two during the meshing transmission process of sprocket wheel and chain;

2. Points of intersection of adjacent curves represent two teeth bearing and carrying equal contact force;

3 . With the rotation of sprocket wheel, sprocket wheel tooth contact force increasing and the anchor chain nest slippage occurs, impact between sprocket wheel and chain appears, the contact force mutates and reaches the maximum value, namely the time when contact force of various sprocket wheel and chain tooth reaches the maximum in the diagram. In this case, two teeth bearing, but one tooth contact force reaches the maximum value.

\section{Strength analysis of sprocket wheel}

According to the results of contact force graph between sprocket wheel and chain, there are three bearing situations in the meshing transmission process of sprocket wheel and chain: Single tooth bearing, two tooth bearing and carrying equal contact force and two tooth bearing but one tooth contact force reaches the maximum value. The third case is a dangerous condition from the perspective of sprocket wheel strength. Teeth load values are listed as follows: $F X 1=880.92 \mathrm{~N}, \mathrm{FY} 1=108268.8 \mathrm{~N}$, $F Z 1=331395.91 \mathrm{~N}, \quad F X 2=466.63 \mathrm{~N}, \quad \mathrm{FY} 2=8110.92 \mathrm{~N}$, $\mathrm{FZ2}=6391.01 \mathrm{~N}$.

Sprocket wheel and Sprocket wheel gear are connected by five bolts and five cylindrical pins. The effective area of the bolt and cylindrical pin are $1152 \mathrm{~mm}^{\wedge} 2$ and $1440 \mathrm{~mm}^{\wedge} 2$. The torque of sprocket wheel in the working phase of anchor is $\mathrm{T}=\mathrm{F} * \mathrm{D} / 2=290 \mathrm{KN} * 1062 \mathrm{~mm} / 2=153990 \mathrm{Nm}$. The results showed that the pressure value of cylinder pin hole and bolt hole are $12.98 \mathrm{Mpa}$ and $16.23 \mathrm{Mpa}$.

In the ANSYS Workbench software, material properties on chain wheel are defined as follows: elastic modulus of 202Gpa, Poisson's ratio of 0.3 , density of $7800 \mathrm{~kg} / \mathrm{m}^{\wedge} 3$. Mesh the procket wheel, add pressure load to bolts and cylindrical pins, then add tooth load, define boundary conditions and take the static analysis. Mesh model of sprocket wheel is shown in Fig. 6. Finite element analysis model of sprocket wheel is shown in Fig. 7.

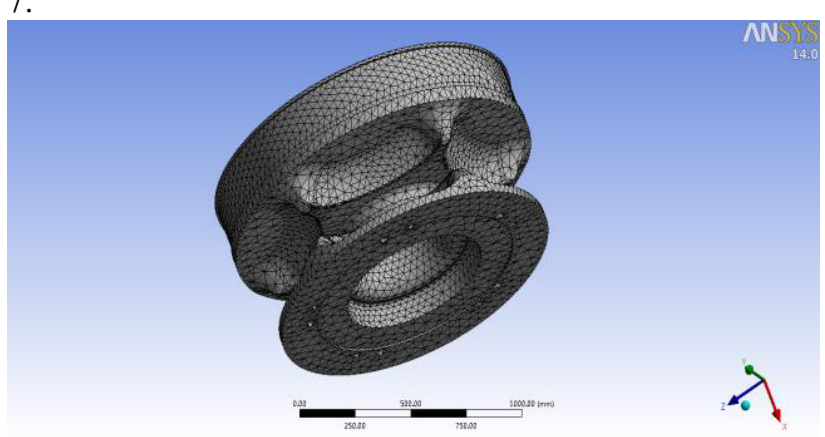

Figure 6. Mesh model of sprocket wheel.

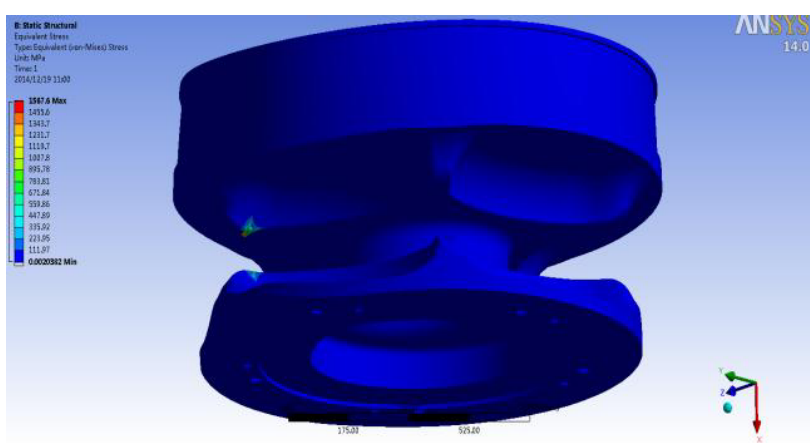

Figure 7. Finite element analysis model of sprocket wheel.

According to the static structural analysis results of sprocket wheel, the equivalent stress figure of sprocket wheel in dangerous conditions is shown in Fig. 8. 


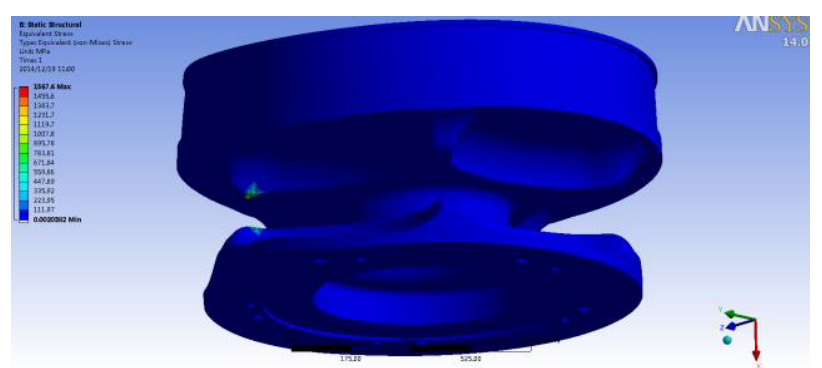

Figure 8. The equivalent stress figure of sprocket wheel in dangerous conditions.

Strength analysis of sprocket wheel are listed as follows: the contact between sprocket wheel and chain belongs to point contact in theory, therefore, stress value at the contact position of sprocket wheel and chain is very large, the maximum equivalent stress reaches $1567.6 \mathrm{Mpa}$. When the stress exceeds the yield limit of the material of sprocket wheel, plastic deformation occurs at the contact position of the sprocket wheel and chain. When the plastic deformation occurs, the contact area of the sprocket wheel and chain increases, the stress value declines sharply. Therefore, sprocket wheel will not be undermined in the actual work process. In addition to the contact position of the sprocket wheel and chain, the equivalent stress values of the remaining parts of the sprocket wheel do not exceed $111.97 \mathrm{Mpa}$, less than the allowable stress of the sprocket wheel material 0.9 $=234 \mathrm{Mpa}$, meet the strength requirements of chain wheel.

\section{Conclusion}

The mechanical characteristics were analyzed in the meshing transmission process of sprocket wheel and chain by RecurDyn. The results showed that: there are three bearing situations in the meshing transmission process of sprocket wheel and chain: Single tooth bearing, two tooth bearing and carrying equal contact force and two tooth bearing but one tooth contact force reaches the maximum value. The third case is a dangerous condition from the perspective of sprocket wheel strength.

As can be seen from the results of static analysis, the equivalent stress value at the contact position of sprocket wheel and chain exceeds the yield stress of the chain wheel material, but it does not cause damage to chain wheel. In addition to this location, the equivalent stress values of the remaining parts of the sprocket wheel are in the allowable stress range of sprocket wheel material, comply with the requirement of strength design.

The equivalent stress cloud graph and the related conclusions of the sprocket wheel through the strength analysis provide a reference for structure optimized design and lightweight design of the windlass.

\section{References}

1. F. C. Hu. Wuhan University of Science and Technology, 1, 8-10 (2007)

2. Z. W. Zhou, R. S. Wang, Manufacturing Automation, 33, 151-153 (2011)

3. Z. X. Fang, L. D. Zhang, Guangdong Shipbuilding, 1, 40-42 (2008)

4. D. L. Liu, Jiangsu Shipping, 19, 37-38 (2002)

5. F. L. Chen, Journal of Shanghai Jiaotong University, 3, 133-150 (1979)

6. Standardization Administration of China, Sprocket wheel, 3179, 4-6 (1996)

7. Y. Lu, X. G. Ma, Q. L. Shu, Transactions of Shenyang Ligong University, 27, 76-79 (2008)

8. X. G. Ma, W. Yang, X. M. You, Chinese Journal of Construction Machinery, 7, 146-152 (2009)

9. X. G. Ma, Y. Lu X. M. You, China Mechanical Engineering, 20, 1956-1959 (2009) 